\title{
Effects of geography, taxa, water flow, and temperature variation on coral bleaching intensity in Mauritius
}

\author{
T. R. McClanahan ${ }^{1, *}$, J. Maina ${ }^{2}$, R. Moothien-Pillay ${ }^{3}$, A. C. Baker ${ }^{1,4}$ \\ ${ }^{1}$ Marine Programs, Wildlife Conservation Society, 2300 Southern Blvd., Bronx, New York 10460, USA \\ ${ }^{2}$ Coral Reef Conservation Project, PO Box 99470, Mombasa, Kenya \\ ${ }^{3}$ Mauritius Oceanographic Institute, Quatre Bornes, Mauritius \\ ${ }^{4}$ Center for Environmental Research and Conservation, Columbia University, 1200 Amsterdam Avenue, \\ New York, New York 10027-5557, USA
}

\begin{abstract}
This study describes the response of common coral taxa at 15 sites to a warm-water anomaly in Mauritius in March 2004. Sites circumscribed the island and differed in their water flow and thermal history as a result of variation in local current patterns. We observed 2 distinct positive responses of coral taxa to the anomaly that correlated with their local abundance, with a group of sparse ( 22 taxa covering $<5 \mathrm{~cm} \mathrm{~m}^{-1}$ ) and abundant taxa $\left(7\right.$ taxa covering $>5 \mathrm{~cm} \mathrm{~m}^{-1}$ ). The 2 most dominant taxa Acropora and Montipora were among the most susceptible genera in the abundant group, while Seriatopora and Alveopora were the most susceptible taxa in the sparse group. This suggests that a temperature anomaly that is sufficient to cause mortality will remove taxa from 2 positions in the community spectrum with consequences for both ecological functions and diversity. We found that bleaching intensity at the sites was positively associated with water flow, with the most intense bleaching and highest currents on the windward and offshore sites. The algal symbiont communities in nearly all of the corals sampled on both sides of the island and 2 depths were dominated by diverse Symbiodinium in Clade $C$, indicating that the observed differences in response among coral taxa and sites were unlikely to be greatly affected by the types of symbionts they contained. We suggest that high water flow reduces background stress and acclimation, and results in corals that are less tolerant of rare temperature anomalies.
\end{abstract}

KEY WORDS: Bleaching $\cdot$ Climate change $\cdot$ Currents $\cdot$ Indian Ocean $\cdot$ Temperature

\section{INTRODUCTION}

It has been predicted that corals in the western Indian Ocean's southern hemisphere will become ecologically extinct within the next 20 to 40 yr (Sheppard 2003). This prediction is based on water temperature patterns associated with the mass coral mortality in 1998, combined with a 0.2 probability of reoccurrence of a similar event in the future; based on the blending of past surface water temperatures to predict future temperatures (Sheppard 2003). Differences in latitude, local oceanographic effects, and coral acclimatization and/or adaptation may, however, override or slow these large-scale predictions (Sheppard 2003, West \& Salm 2003, Baker et al. 2004). For example, despite widespread coral bleaching and mortality in the western Indian Ocean in 1998 (Wilkinson et al. 1999, Goreau et al. 2000), $<10 \%$ of the corals in Mauritius were bleached, with most of the bleaching occurring in the bleaching-sensitive genus Acropora (Moothien Pillay et al. 2002). This may have been due to chance occurrences, such as the presence of clouds or storms (Turner et al. 2000), but may also be attributed to more deterministic factors such as geography and tempera- 
ture histories (Berkelmans et al. 2004), the coral taxa involved (McClanahan 2004), the dominant algal symbionts on these reefs (Baker et al. 2004) and water flow (Nakamura \& van Woesik 2001).

Here we examine the importance of the above factors in influencing bleaching intensity during the peak of a strong bleaching event in early 2004, when water temperatures exceeded the local bleaching threshold of $\sim 27.5^{\circ} \mathrm{C}$ (G. Liu, NOAA, unpubl. data). We examine bleaching patterns circumscribing the island of Mauritius, where an estimate of bleaching intensity was calculated for each taxon and reef (McClanahan 2004), water-flow estimates were made, water temperature histories were calculated from satellite and local meteorological data, and a study of algal symbiont diversity and distribution in corals from 4 sites before bleaching (November 2002) was completed. This study aimed to describe the general responses of different hard coral taxa and reef sites to this bleaching event, and in so doing, to identify the factors that influence bleaching and determine future patterns of bleaching on these potentially vulnerable reefs.

\section{MATERIALS AND METHODS}

Study sites. The island of Mauritius lies between latitudes 19.58 and $20.31^{\circ} \mathrm{S}$, and longitudes 57.18 and $57.46^{\circ} \mathrm{E}$ in the southwestern Indian Ocean. It has a $\sim 200 \mathrm{~km}$ coastline and is nearly completely surrounded by a fringing coral reef of over $150 \mathrm{~km}^{2}$ in extent. The width of the lagoon from shore to reef crest is quite variable, ranging from $400 \mathrm{~m}$ in certain areas, up to nearly $7 \mathrm{~km}$ off the eastern coast, with a depth of 1 to $2 \mathrm{~m}$. Tides are semi-diurnal with a mean tidal range of $0.90 \mathrm{~m}$ during spring tide and $0.1 \mathrm{~m}$ during neap tide (Montaggioni \& Faure 1997). Mauritian climate is characterized by 2 alternating seasons: (1) a hot and rainy summer from November to April and (2) a mild winter from May to October. Sea surface temperature (SST) varies seasonally, with a low of $23^{\circ} \mathrm{C}$ in August and a high of $27^{\circ} \mathrm{C}$ in February (Ragoonaden 1997). However, at times, SST rises close to $29^{\circ} \mathrm{C}$ in summer and may drop to $22^{\circ} \mathrm{C}$ in winter (Ragoonaden 1997). The dominant current patterns are from east to west, and are influenced by the southeast trade winds, which are stronger during the winter months. During the summer months, weaker sea breezes from the northwest are a common occurrence.

We chose 15 sites from 7 locations to measure benthic cover and water flow (Fig. 1). Due to logistical problems, only 14 sites were sampled for the bleaching response. Locations were chosen to represent all sides of the island and the 15 study sites were representative of the various back-reef coral communities in each of the regions. Reefs were sampled from 3 to 24 March 2004, just after the peak water temperatures in February.

Temperature measures. SSTs were calculated from a combination of a NOAA Pathfinder (Version 4) satellite data set for the period 1985 to 2003 and from the Mauritius Meteorological Services in situ data set for the period 2001 to 2004. The satellite data, which had a resolution of $9 \mathrm{~km}$, consisted of 4 time series at 4 satellite pixels for each study location and was calculated for the area 19.91 to $20.52^{\circ} \mathrm{S} ; 57.0$ to $57.88^{\circ} \mathrm{E}$ (G. Liu unpubl. data). We examined the $4 \mathrm{~km}$ resolution data but found the density of data to be too low and, therefore, used the $9 \mathrm{~km}$ data. Monthly data from the Meteorological Services were obtained from a Wave-rider Buoy set at $\sim 1 \mathrm{~km}$ offshore in a water depth of $57 \mathrm{~m}$ off Blue Bay Coast, off the island's SE coast. We examined rainfall and hours of sunshine data from the Mauritius meteorological department but did not observe unusual anomalies and, therefore, do not present these data.

Water-flow measures. We estimated water flow using clod cards deployed at each of the study sites. Clod cards were prepared according to the general instructions of Doty (1971). The clods were manufactured by mixing commercial plaster of Paris (calcium sulfate) with fresh water to make a thick mixture with

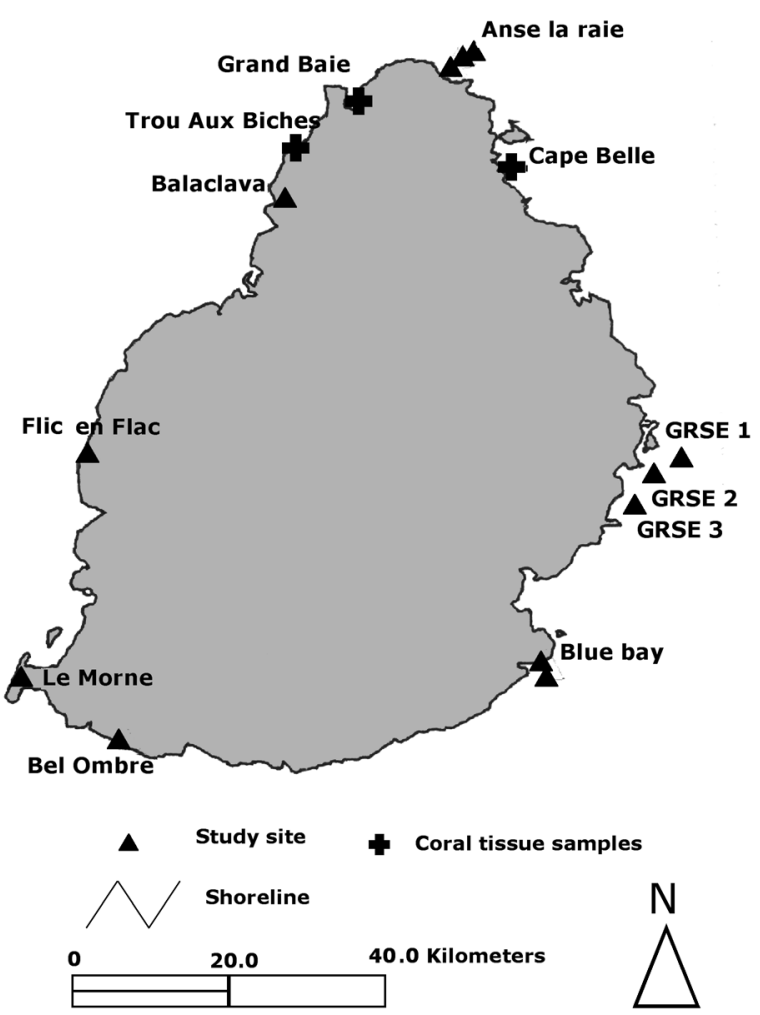

Fig. 1. Benthic field and coral tissue sampling sites in Mauritius 
an approximate ratio of $90 \mathrm{ml}$ of water to $100 \mathrm{~g}$ of calcium sulfate. All clods were made from a single mixture to ensure the same consistency and starting point. The mixture was poured into a plastic ice cube tray for molding where all cubes were of the same size. The plastic ice cube tray was smeared beforehand with vegetable oil to prevent the clods from sticking to the plastic surface. The molds were tapped vigorously against the table top until the bubbles stopped rising to the surface, before being allowing to harden at room temperature for about $48 \mathrm{~h}$. Water-resistant flat plastic bases of $\approx 8 \mathrm{~cm}^{2}$ were cut and holes punched in each of the 4 corners to allow cards to be fastened to substrata in the field. The clods were then removed from the molds and glued onto the flat bases using epoxy. Having secured the dried clods on the flat bases, they were weighed and marked, and the initial weight recorded at the base using a water-resistant felt pen.

In the field, the clod cards were tied to corals and coral rocks using thin plastic-covered wire. Two clod cards were secured to a coral on the upper surface of growth, such that the cards were exposed to full currents and left overnight to be collected after $\sim 24 \mathrm{~h}$. Exact deployment and collection times were recorded and used to calculate the deployment time and rate of dissolution. On removal, the clod cards were left to dry in full sunlight for not less than $2 \mathrm{~d}$. Final weight was taken and weight loss calculated. Current speed in $\mathrm{g}$ $\mathrm{d}^{-1}(24 \mathrm{~h})$ was obtained by dividing weight loss by deployment time. Weight loss [g] was then converted to flow speed $\left(V_{\mathrm{w}}=\mathrm{cm} \mathrm{s}^{-1}\right)$ using the equation $V_{\mathrm{w}}=$ $\left(\mathrm{D} W_{\text {clod }}-0.932\right) / 2.357$, which was obtained by studies of clod dissolution in a flume with controlled water flow (Anzai 2001).

Algal symbiont identification and analyses. Coral samples were collected between 2 and 11 November 2002 from 4 sites along the southeast (Blue Bay), northeast (Cape Belle) and northwest coasts (Grand Bay and Trou aux Biches) (Fig. 1, Table). Snorkelers (2 m depth: Cape Belle, Grand Bay, Blue Bay) or divers (15 m depth: Trou aux Biches) collected tissue samples (each $\sim 1$ to $3 \mathrm{~cm}^{2}$ ) from 11 scleractinian species of 5 genera ( $\mathrm{n}=35$ total). Samples were preserved at room temperature in 2 to $4 \mathrm{ml}$ of saline DMSO (Seutin et al. 1991), and total DNA extracted using established methods (Baker et al. 1997). Symbiont DNA was amplified using partial large subunit ribosomal DNA (LSU rDNA) primers 24D15F4 and 24D23R1, and the resultant products identified and assigned to clades using restriction fragment length polymorphism (RFLP) analysis using the enzymes TaqI and HhaI (Baker \& Rowan 1997, Baker et al. 1997, Baker 2001).

Benthic surveys. Corals and benthic cover were examined using standard line-intercept transects to describe the cover of the major functional groups and dominant coral taxa (McClanahan \& Shafir 1990). At each of the 15 study sites, nine $10 \mathrm{~m}$ line transects were haphazardly placed in areas dominated by hard corals. Hard corals under the line and $>3 \mathrm{~cm}$ in transect length were identified to the genus level and measured to the nearest centimeter (McClanahan \& Shafir 1990). The subgenus Synarea (=Porites rus) as well as branching and massive Porites were also distinguished because they differ considerably in their response to warm water (McClanahan et al. 2001, Yap 2004). Cover of these taxa was calculated as numbers of $\mathrm{cm}$ per meter of line transect. To estimate the hard coral taxonomic richness of a site beyond the limit of the $90 \mathrm{~m}$ of line transect, a time-sampling procedure was used where an observer recorded the number of genera observed during a 40 min search sampling interval (McClanahan \& Muthiga 1992). During the sampling, the observer swam haphazardly along the shallow reef sites and recorded the time taken to observe the first individual of a coral genus. The number of taxa per site by this method is correlated with the number of taxa by the line transect method $(r=0.76, p<0.002)$ but produces more rare taxa and was, therefore, used to test for relationships with other environmental and biological variables.

Bleaching indices. At 14 of the study sites, the intensity of bleaching was estimated by evaluating the color intensity of haphazardly selected corals (McClanahan et al. 2001, McClanahan 2004). Colonies were sampled by swimming with closed eyes above the reef in a randomly chosen direction, kicking a random number of kicks between 3 and 7 , and upon opening the eyes, all corals colonies within a $2 \mathrm{~m}$ radius were selected for color intensity categorization. This process was repeated at each site, such that between 322 and 735 coral colonies were sampled per site. A total of 6662 colonies of 32 taxa were sampled for the study.

Colonies were allocated to the following 6 categories: (1) unbleached (normal coloration), (2) pale (lighter color than usual for the time of year), (3) 0 to $20 \%$ of the surface bleached, (4) 20 to $50 \%$ bleached, (5) 50 to $80 \%$ bleached and (6) 80 to $100 \%$ bleached. Gleason (1993) originally described the method, McClanahan et al. (2004) compared it between regions, and Edmunds et al. (2003) validated it by comparison with symbiont density and color.

A Bleaching Index (BI) was calculated from the percentage of observations in each of the above 6 bleaching categories over the 5 sampling periods as:

$$
\mathrm{BI}=\left(0 c_{1}+1 c_{2}+2 c_{3}+3 c_{4}+4 c_{5}+5 c_{6}\right) / 5
$$

where $C$ is the percentage of observations in each of the above 6 bleaching categories. This index can be calculated for each taxon and by pooling all taxa for each site. 
Data analyses. Satellite-based time series from advanced very high-resolution radiometers (AVHRR) on board NOAA polar orbiting satellites have been obtained over the past $20 \mathrm{yr}$ and have been shown to provide accurate and useful SST observations. The data with a $9 \mathrm{~km}$ spatial resolution used here dates back to January 1985. We obtained SST data for 8 stations at various positions between latitudes 19.91 and $20.52^{\circ} \mathrm{S}$, and longitudes 57.09 to $57.88^{\circ} \mathrm{E}$. Coordinates of the station GPS were matched to those of the study sites, and the temperature data were assigned to each site on this basis. Due to the coarse spatial resolution of the SST data, sites from the same reef had the same temperature dataset except Flic en Flac where Site 1 and Site 2 were matched to separate datasets. We analyzed the data for temperature variation on each reef from 1985, and plotted the standard deviations and water flow measures against the respective reef longitudes to determine whether there was an eastwest gradient of temperature variation and/or waterflow. Additionally, we also counted the number of days that the SST was above the $27.5^{\circ} \mathrm{C}$-bleaching threshold and expressed it as a percentage of the total sampling days. From these, we obtained a percentage mean anomaly for each reef, and correlated it with longitude and temperature variation. We found that the temperature variation was a better predictor of bleach- ing than the temperature anomaly and, therefore used it in the multiple regression models described below.

The BI calculation can be used to determine the response of each taxon and all taxa combined to obtain a site-specific BI. The taxa-specific BI for all sites combined was used to determine the susceptibility of the various taxa, the relationship between bleaching and abundance, and was compared with the same indices for similar bleached coral taxa studied in Kenya in 1998; this was one of the strongest recorded bleaching events in recent history (McClanahan et al. 2003). Bleaching measurements in both cases were taken during the peak periods of bleaching. To be included in these regression analyses, more than 6 individuals from each region had to be sampled, which resulted in 20 comparable taxa.

The site-specific BI can be used to determine local responses of organisms to warm water, but could be confounded if it were influenced by differences in the community composition of corals at each site. To determine whether the site-specific BI was being influenced by the composition of taxa at each site, we performed a covariance-based principal component analysis (PCA) on the 26 dominant coral taxa and 15 sites, and correlated the first and second components or $x$ and $y$ Eigenvalues against the BI (Sall et al. 2001). The first 2 components of the PCA predicted 58 and $33 \%$ of the variance

Table 1. Systematic and ecological distribution of algal symbionts in scleractinian corals from Mauritius. n: total number of independent colonies sampled. When multiple symbiont taxa were found in the same coral taxon at the same site, the depth distribution of these symbionts is recorded in the right-hand column as symbiont genotype followed by the number of colonies containing that genotype, and their depth, in parentheses. For example: $C 1(1: 2.0)$ and $C 4$ (4:2.0) indicate that Symbiodinium $C 1$ was recorded in 1 colony at $2 \mathrm{~m}$, while Symbiodinium $C 4$ was recorded in 4 colonies at $2 \mathrm{~m}$. Symbiont genotypes follow LSU rDNA nomenclature presented in Baker (1999)

\begin{tabular}{|c|c|c|c|c|c|}
\hline Scleractinian coral & Location & $\mathrm{n}$ & $\begin{array}{l}\text { Depth } \\
(\mathrm{m})\end{array}$ & $\begin{array}{l}\text { Symbiont } \\
\text { genotype }\end{array}$ & $\begin{array}{l}\text { Depth distribution of genotypes } \\
\text { (no.of colonies: depth [m]) }\end{array}$ \\
\hline \multicolumn{6}{|l|}{ Acroporidae } \\
\hline \multirow[t]{3}{*}{ Acropora formosa } & Blue Bay & 2 & 2.0 & $C 4$ & - \\
\hline & Cape Belle & 6 & 2.0 & $A, C 1, C 4$ & $A+C 4(1: 2.0), C 1(1: 2.0), C 4(4: 2.0)$ \\
\hline & Grand Bay & 2 & 2.0 & $C 4$ & - \\
\hline \multicolumn{6}{|l|}{ Pocilloporidae } \\
\hline \multirow[t]{2}{*}{ Pocillopora damicornis } & Blue Bay & 1 & 2.0 & $C_{\mathrm{pp}}$ & - \\
\hline & Cape Belle & 4 & 2.0 & $C 1, C 2, C 5$ & $C 1(1: 2.0), C 2(1: 2.0), C 5(2: 2.0)$ \\
\hline \multirow[t]{3}{*}{ Pocillopora verrucosa } & Cape Belle & 2 & 2.0 & $C_{\mathrm{pp}}$ & - \\
\hline & Grand Bay & 3 & 2.0 & $C 1, C_{\mathrm{pp}}$ & $C 1(1: 2.0), C_{\mathrm{pp}}(2: 2.0)$ \\
\hline & Trou aux Biches & 2 & 15.0 & $C 1, C 4$ & C1 (1:15.0), C4 (1:15.0) \\
\hline \multicolumn{6}{|l|}{ Oculinidae } \\
\hline \multirow[t]{3}{*}{ Galaxea fascicularis } & Blue Bay & 1 & 2.0 & $C 4$ & - \\
\hline & Grand Bay & 2 & 2.0 & $C 1$ or $D_{\mathrm{dh}}$ & $C 1(1: 2.0), D_{\mathrm{dh}}(1: 2.0)$ \\
\hline & Trou aux Biches & 1 & 15.0 & $C 1$ & - \\
\hline \multicolumn{6}{|l|}{ Poritidae } \\
\hline \multirow[t]{2}{*}{ Porites (massive) } & Cape Belle & 1 & 2.0 & $C 1$ & - \\
\hline & Grand Bay & 3 & 2.0 & $C 1$ & - \\
\hline \multicolumn{6}{|l|}{ Agariciidae } \\
\hline Pavona frondifera/decussata & Grand Bay & 1 & 2.0 & $C_{\mathrm{pp}}$ & - \\
\hline \multirow[t]{2}{*}{ Pavona varians } & Grand Bay & 2 & 2.0 & $C 1, C_{\mathrm{pp}}$ & $C 1(1: 2.0), C_{\mathrm{pp}}(1: 2.0)$ \\
\hline & Trou aux Biches & 2 & 15.0 & $C 1$ & \\
\hline
\end{tabular}


in the data but these individually or in combination were not significantly correlated with the BI. Consequently, the site-specific BI can be seen as independent of the taxonomic composition of the corals at the site. The site-specific BI and the number of taxa at a site were regressed against water flow and the standard deviation of the full record of the NOAA temperature, while Pearson-product correlations were used to test for associations between longitude, current speed, and temperature variation.

To determine the combination of factors that predicted the site-specific bleaching index and the taxonomic richness of hard corals, we performed a multiple regression with the BI and numbers of taxa as the response variables, and current speed, standard deviation of the full record of NOAA temperature, and longitude and latitude and their interaction, as the independent variables. If the model did not significantly explain the variation in $\mathrm{BI}$, we removed the weak factors in the model and repeated the analysis.

\section{RESULTS}

\section{Water temperature and flow trends}

The mean water temperature from the Wave-rider buoy of the Mauritius Meteorological Services in February 2004 was $28.6^{\circ} \mathrm{C}$, which is approximately $1^{\circ} \mathrm{C}$ above the reported long-term average for this month of $27.7^{\circ} \mathrm{C}$ (Fig. 2). The warm season in 2004 was the last of 4 unusually warm years starting in 2001. Warm summer months prior to this series of consecutive warm months were measured in 1987, 1988, 1991 and 1998. February 1987 and 2004 were the 2 warmest months from this record but 2004 is unique in having 3 prior warm years. Long-term temperature variation and anomalies from the NOAA satellite data were strongly negatively correlated with longitude $(\mathrm{r}=-0.92, \mathrm{p}<$ 0.0001), with standard deviations declining from 1.82 to 1.73 , and 18 to $11 \%$ of the measurements from the southwestern to northeastern side of the island (Fig. 3). Water flow was weakly positively correlated with longitude for all sites $(r=0.50, p=0.069)$. Temperature variation and current speed were weakly negatively associated $(r=-0.50, p=0.068)$.

\section{Symbiont identifications}

All samples analyzed $(n=35)$ contained members of Symbiodinium Clade $C$, with the exception of 1 sample of Galaxea fascicularis from a $2 \mathrm{~m}$ depth at Grand Bay (northwest coast), which contained Symbiodinium $D$, and 1 sample of Acropora formosa at a $2 \mathrm{~m}$ depth from Cape Belle (northeast coast), which contained a mixed community of Symbiodinium A with Symbiodinium C4 (nomenclature as in Baker 1999). The remaining 34 samples contained Symbiodinium C1, C2, C4, C5, or $C_{\mathrm{pp}}$, with no evidence for mixed symbiont communities within these colonies (Table 1).

In terms of diversity, symbiont communities from shallow $(2 \mathrm{~m})$ sites on the northeast coast (Blue Bay and Cape Belle) contained 6 types of Symbiodinium $(A, C 1$, $\left.C 2, C 4, C 5, C_{\mathrm{pp}}\right)$, compared to symbiont communities from a shallow site on the northwest coast (Grand Bay), which included 4 types of Symbiodinium $\left(C 1, C 4, C_{\mathrm{pp}}\right.$, $D$ ). A deep (15 m) site on the northwest coast (Trou aux Biches) contained only 2 types of Symbiodinium (C1, C4). Small sample sizes and the different coral hosts sampled prevent a meaningful comparison of symbiont distributions between individual sites, but on a cladal level there is no evidence for differences between the 2 shallow northeast coast sites (C: $97 \%, D: 3 \%, A: 0 \%)$ and the one shallow northwest coast site $(C: 92 \%, D$ : $8 \%, A: 0 \%)\left(\chi^{2}=1.71, \mathrm{df}=2, \mathrm{p}>>0.05\right)$.

\section{Taxon-specific bleaching responses}

Combining the 6662 sampled coral colonies, normal and pale corals accounted for 47 and $29 \%$, respectively while $24 \%$ of the colonies were bleached with $20 \%$ severely bleached ( 80 to $100 \%$ ), and only $1 \%$ had recently died (Fig. 4). There were large differences in 

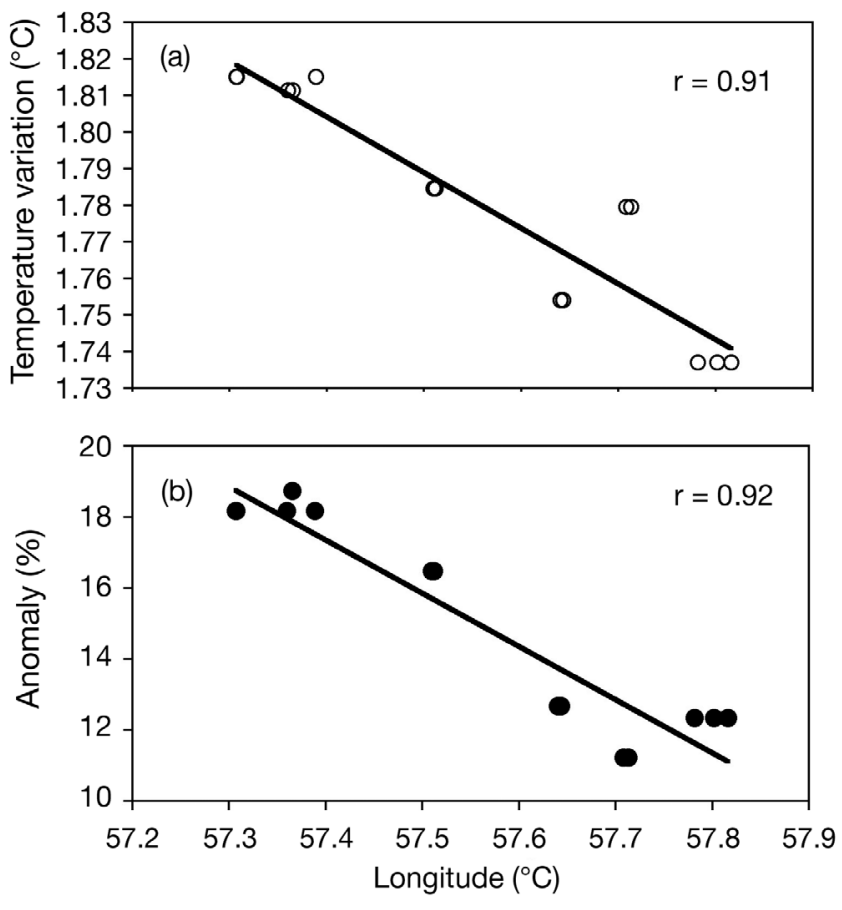

Fig. 3. Scatter plots of the relationship between the longitude of the study sites and (a) temperature variation (SD) and (b) anomaly (\% observations $>27.5^{\circ} \mathrm{C}$ )

the susceptibility of the studied taxa, ranging from an undetectable response for Coscinarea, Leptastrea and Stylophora to bleaching indices above 60 for Seriatopora and Alveopora (Fig. 5a). Coscinarea and Stylophora were quite rare, however, being found at only 1 site and with small sample sizes, while Leptastrea was found at 3 study sites. The most susceptible genera Seriatopora and Alveopora were also uncommon corals, being present at less than $4 \mathrm{~cm} \mathrm{~m}^{-1}$ of the substratum (Fig. 5b). There was no clear relationship between coral abundance and bleaching intensity when examining all coral taxa together but there was a clearly observed cutoff at approximately $5 \mathrm{~cm} \mathrm{~m}^{-1}$ that separates the response between sparse and abundant corals, and these 2 groups analyzed separately produce significant positive relationships (Fig. 5b). The relationship is strongest for the 7 most abundant corals, with the 2 most common taxa Acropora and Montipora being moderately susceptible to bleaching and Pavona being the least susceptible to bleaching.

Based on the BI, bleaching in Mauritius had a bleaching intensity of about $25 \%$ of that observed in Kenya in 1998. A regression between the taxa-specific BI of Mauritian and Kenyan corals suggests that these responses were generally consistent between countries, but there was also considerable scatter in the data. Accounting for this difference with the slope of the regression line and $95 \%$ confidence intervals, the genera Hydnopora, Turbinaria, Astreopora, Porites, Fungia and Pocillopora bleached less, while Cyphastrea, Millepora and Acropora bleached proportionally more in Mauritius than in Kenya (Fig. 6).

A bivariate plot of taxa richness against temperature variation revealed a positive relationship between richness and temperature variation (Fig. 7a), and a negative relationship with hard coral cover (Fig. 7b). Taxa richness was, however, not well predicted by a multiple regression model with all environmental factors except when temperature variation was excluded (Table 2). The model without temperature variation explained $65 \%$ of the variation in taxonomic richness, with longitude and its interaction with latitude contributing significantly to the variation caused by the model (Table 2).

\section{Site-specific bleaching responses}

Regression analysis revealed a positive relationship between the site-specific BI and current speed (Fig. 8). The multiple regression model, which included all the factors explained $65 \%$ of the total variation in the BI. This combination of factors did not, however, significantly explain the variation in BI (whole model test: $\mathrm{p}>$ 0.05). When each factor was tested for its contribution to the total explained variation, current speed was found to contribute a significant proportion $(\mathrm{p}<0.05)$, while latitude, longitude, temperature variation and the latitude-longitude interaction did not (Table 3a). We found the combination of current speed, temperature variation and longitude to significantly predict the variation in the BI (whole model test: $\mathrm{p}<0.05$ ), where only water flow contributed significantly to the total variation explained by the model (Table $3 b$ ).

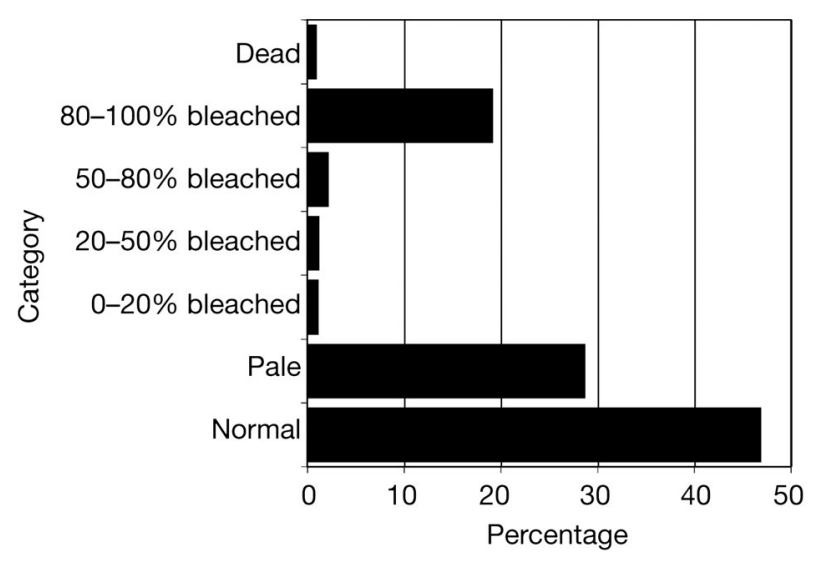

Fig. 4. Summary of the bleaching responses of all 6662 studied corals pooled into the 7 colors or categories of bleaching 


\section{DISCUSSION}

\section{The environment}

This study examined the taxa and sitespecific responses of scleractinian corals to a unique warm-water anomaly in order to test the effects of environmental factors associated with island geography on the intensity of bleaching. Given that this study was undertaken in one of the 2 warmest summers in the past $20 \mathrm{yr}$ and that it was preceded by $3 \mathrm{yr}$ of rising temperatures, this may have been one of the most intense and widespread bleaching events on this island in recent history. Studies in 1998 suggest a modest response to this warm water with reports of only $10 \%$ of the colonies being bleached (MoothienPillay et al. 2002) compared to $24 \%$ in this study. Although there are anecdotal reports of mild bleaching in 2001, 2002 and 2003 in Mauritius and in nearby Rodrigues, this appears to be the most affected year in the recent past (Hardman et al. 2004, Mauritian Fisheries Department unpubl. data, R. Moothien-Pillay pers. obs.). The reported high temperature here of $28.6^{\circ} \mathrm{C}$ is $\sim 1^{\circ} \mathrm{C}$ above the suggested bleaching threshold of $27.5^{\circ} \mathrm{C}$ and the long-term February mean of $27.7^{\circ} \mathrm{C}$. Consequently, this year was probably one of the best in recent history to study the response of Mauritian corals to a rare warm-water anomaly. This study further demonstrates that although many reefs in the world bleach at around 30 to $31^{\circ} \mathrm{C}$, the threshold for bleaching can differ significantly from this and is probably reduced considerably in cool low-latitude reefs such as Mauritius (Jokiel 2004).

Temperature variation and anomalies around the island appear to be related to the geographic position, with the southwest side of the island having the highest and the northeast having the lowest temperature variations. This pattern is consistent with the dominant oceanic current patterns that first contact the east side of the island. The oceanic current would, therefore, be the most stable temperature environment and some combination of upwelling, gyres and retention on the leeward side of the island create greater temperature variation. Smaller differences in current and temperature variation between the south and the north side of the island require further investigation.
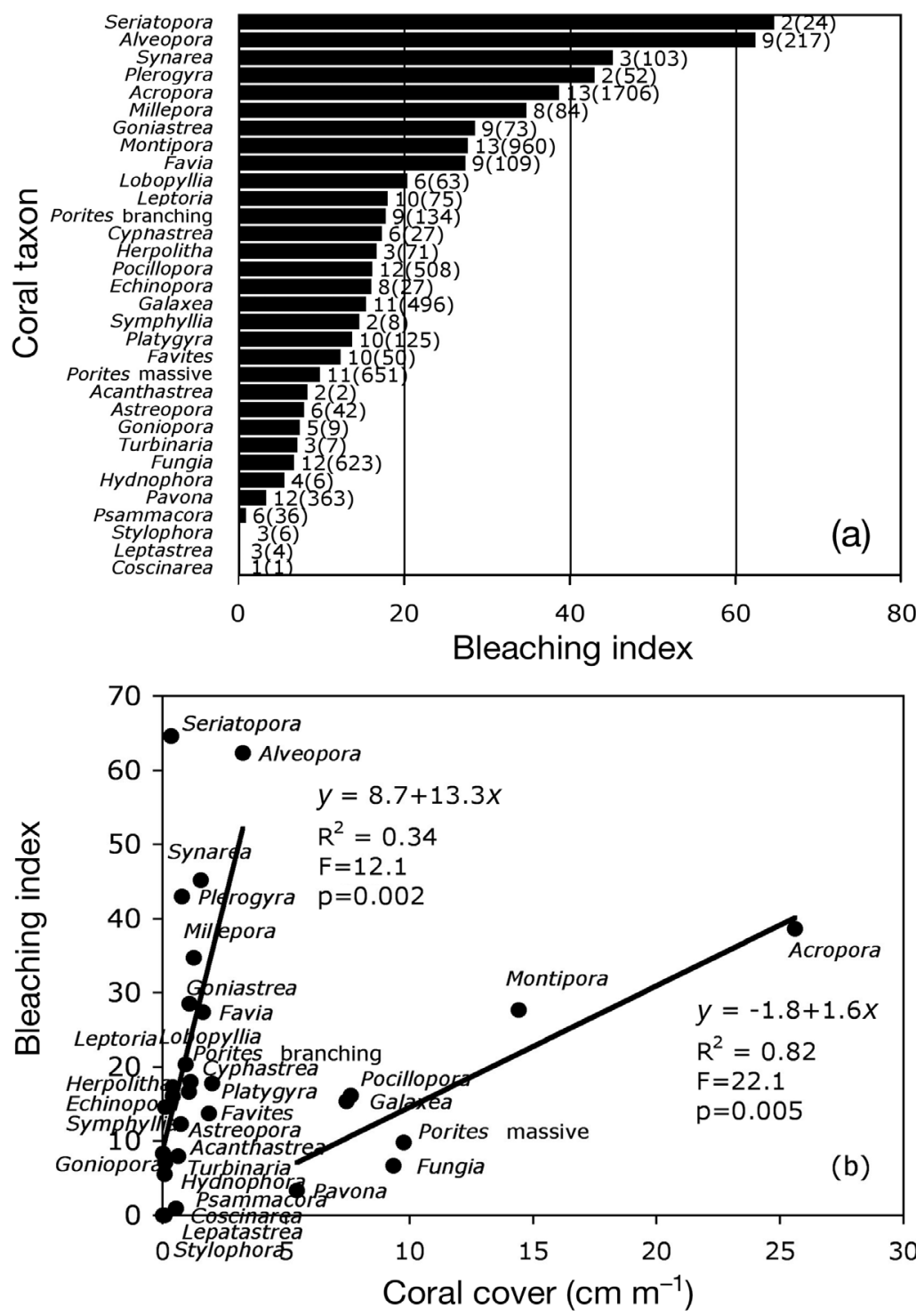

Fig. 5. (a) Taxa-specific bleaching indices sorted from most to least susceptible. The number of sites where each taxon was found and the number of individuals sampled (in parentheses) is presented to the right of the histogram. (b) Bleaching indices as a function of the taxa's contributions to the benthic cover. The analyses split taxa into 2 groups based on the observed difference in responses at $\sim 5 \mathrm{~cm} \mathrm{~m}^{-1}$

\section{Symbiont communities}

It was fortunate for this study that moderate sampling of Mauritian coral tissue had taken place prior to this bleaching event in November 2002. This allowed us to assess the potential effect of different Symbiodinium taxa in explaining variation in coral response to a temperature anomaly. We took samples from both sides of the island and at 2 different depths to determine whether there were differences in these environments that might influence Symbiodinium community distrib- 


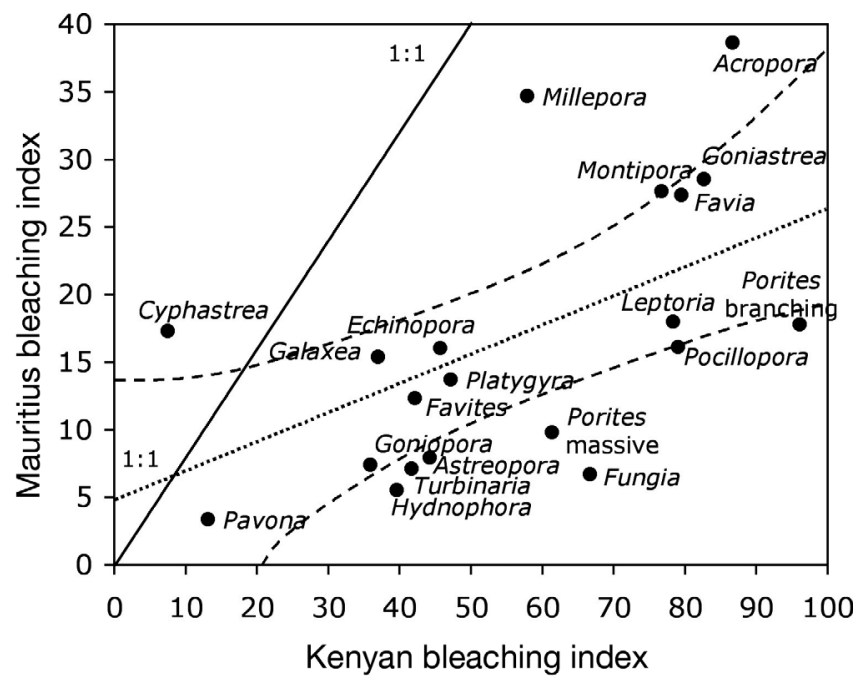

Fig. 6. Comparison of the bleaching indices at Mauritius in 2004 with the response in Kenya during 1998. Best-fit line and confidence interval to the slope are presented as well as the 1:1 line

ution and hence the response of these coral hosts to warm-temperature anomalies. From these preliminary data, Mauritian corals appear to be/have been dominated by diverse members of Symbiodinium clade $C$,

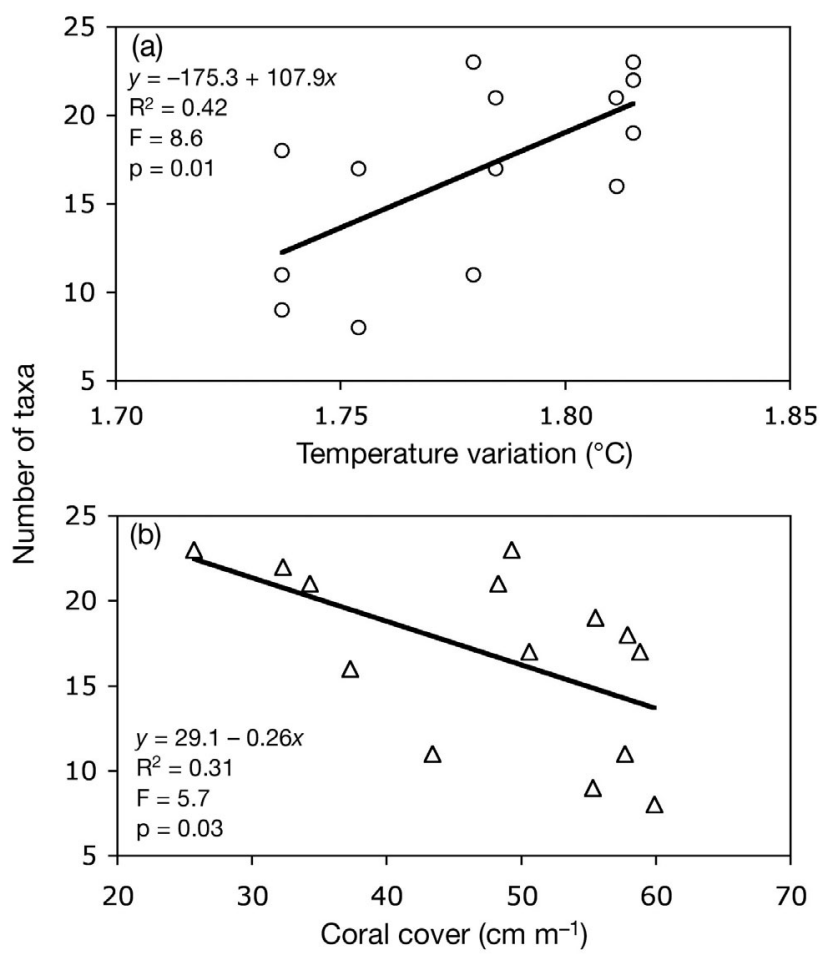

Fig. 7. Coral taxonomic richness as a function of (a) temperature variation and (b) coral cover. Richness is determined from 40 min search intervals at each study site with representatives of Symbiodinium clades $A$ and $D$ being present at very low abundances. First, this uniformity suggests that the bleaching responses we observed were not influenced significantly by which clade of Symbiodinium the corals contained. Due to the small sample sizes and the haphazard sampling of coral hosts, however, future monitoring involving replicate sampling of conspecific hosts at the same depth from different sites will be necessary to more fully address possible effects of differences in species within clade $C$ on the bleaching response. Secondly, although we cannot distinguish a priori what the thermal tolerance of clade $C$ algae may have been from their cladal identity alone, the fact that there was very little Symbiodinium $D$ in any of the corals sampled (1 of 35 colonies, $2.9 \%$ ) suggests that these reefs may have been relatively pristine in terms of bleaching effects (Baker 2004). This is particularly true in light of the fact that symbiont distributions on reefs in the region, such as Kenya, were severely affected by bleaching in 1997-98 and a high proportion of clade $D$ was found in 2001-02 (Baker et al. 2004). The extent to which the proportions of these clades have shifted as a result of bleaching in 2004 is not yet known, but will likely depend on the overall severity of bleaching and mortality in the area.

Data presented here suggest that the 2004 event was moderate and may, therefore, not significantly change the Symbiodinium community composition. Future monitoring of these reefs and others in the central and western Indian Ocean would be useful in determining the pace and direction of possible symbiont shifts. Nonetheless, local physiological acclimatization of coral-algal symbioses to low water flow and possibly

Table 2. Multiple regression output with the number of taxa at 15 sites as the response variable when (a) all factors and (b) selected environmental factors are included as the regressor variables

\begin{tabular}{|c|c|c|c|}
\hline & df & F-ratio & $\mathrm{p}>F$ \\
\hline \multicolumn{4}{|c|}{ (a) Whole model: all variables $\left(\mathrm{R}^{2}=0.68\right)$} \\
\hline & 5 & 2.95 & 0.09 \\
\hline \multicolumn{4}{|l|}{ Effect tests } \\
\hline Longitude & 1 & 0.02 & 0.89 \\
\hline Latitude & 1 & 1.1 & 0.32 \\
\hline Latitude $\times$ Longitude & 1 & 2.2 & 0.18 \\
\hline Current speed & 1 & 2.2 & 0.19 \\
\hline Temperature variation & 1 & 0.4 & 0.54 \\
\hline \multicolumn{4}{|c|}{ (b) Whole model: selected variables $\left(R^{2}=0.66\right)$} \\
\hline & 4 & 3.9 & 0.05 \\
\hline \multicolumn{4}{|l|}{ Effect tests } \\
\hline Latitude & 1 & 2.3 & 0.16 \\
\hline Longitude & 1 & 6.2 & 0.04 \\
\hline Longitude $\times$ Latitude & 1 & 8.3 & 0.02 \\
\hline Current speed & 1 & 4.3 & 0.07 \\
\hline
\end{tabular}




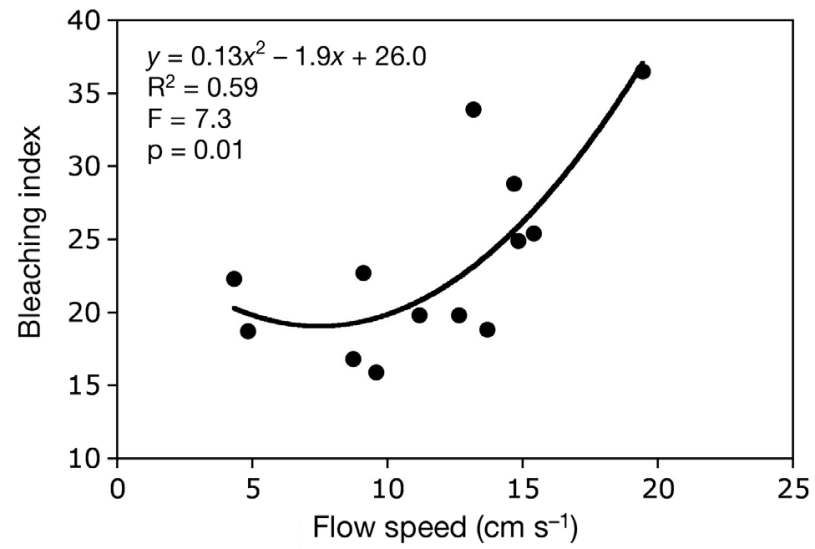

Fig. 8. Bleaching indices at Mauritius in 2004 as a function of the water flow at the study sites along with best-fit statistics

to higher levels of environmental stress remains, at present, a more likely possibility in explaining the observed patterns than differences in taxonomic composition of affected symbiont communities.

\section{Taxa-specific responses}

This study provides further support that the bleaching response is taxa-specific but also with some important species-, region-, or environment-specific differences (McClanahan et al. 2004). Some taxa such as Galaxea, Goniopora, Favites and Pavona have consistently been moderately resistant to bleaching. Acropora and Montipora are among the more susceptible genera, although there are important species-level differences (Baird \& Marshall 2002). Some genera, such as Acropora, Astreopora, Cyphastrea, Fungia, Millepora, Pocillopora, Porites and Turbinaria appear to vary between regions, environments, and species (Glynn \& de Werdt 1991, Gleason 1993, Hoegh-Guldberg \& Salvat 1995, McClanahan 2000, Baird \& Marshall 2002, McClanahan et al. 2004, Yap 2004). Stylophora was not found in Mauritius in sufficient numbers to make meaningful comparisons, but the few colonies found indicated a naturally light coloration that may not be as susceptible to bleaching compared to the darker colored colonies observed in Kenya and the Great Barrier Reef (R. Moothien Pillay pers. obs.). These findings suggest that the acclimatization of coral hosts and algal symbionts, alone or in combination, to different environmental conditions are important in determining reef coral response to warm-water anomalies.

Relationships between bleaching susceptibility and abundance appeared to differ between the many sparse and fewer abundant taxa, although the BI generally increased with increased abundance when the 2 groups were analyzed separately. Sparse taxa, as a group, have a highly variable bleaching response and contain the most and least susceptible taxa. The 7 most abundant taxa, ranging from 5 to $25 \mathrm{~cm} \mathrm{~m}^{-1}$ of the substratum, appeared to have a close positive relationship between abundance and susceptibility to bleaching. It is likely that this relationship reflects the growth rates of these taxa, with the fastest growing taxa contributing the most to coral cover and also being most susceptible to bleaching, suggesting a tradeoff (Gates \& Edmunds 1999). Nonetheless, the bleaching and abundance patterns we observed were different for sparse and abundant taxa, making the growth-bleaching trade-off generalization unlikely for scleractinian corals as a whole taxonomic assemblage. Why some taxa are sparse/common and bleaching resistant/ tolerant is, however, likely to be complicated and influenced by more factors than growth rates and abundance. Nevertheless, the 2 different responses indicate that bleaching will mostly affect taxa at 2 positions along the community-abundance spectrum, with moderately abundant and extremely rare taxa being the least affected. This is likely to have considerable consequences for both species richness and ecological functions, depending on the relationship between bleaching and mortality and the long-term population responses of the intermediate and rare taxa.

The relationship between coral bleaching and mortality is contested and variable (McClanahan 2004). Given that symbiont abundances and chlorophyll concentrations change over the course of a season (Fagoonee et al. 1999), and that bleaching is simply the extreme visual end of a high temperature and light response (Fitt et al. 2001, Edmunds et al. 2003), there need not be a clear relationship. Minor events are

Table 3. Multiple regression output with the bleaching index at 15 sites as the response variable when (a) all factors and (b) selected factors are included as the regressor variables

\begin{tabular}{|c|c|c|c|}
\hline & df & $F$-ratio & $\mathrm{p}>F$ \\
\hline \multicolumn{4}{|c|}{ (a) Whole model: all variables $\left(\mathrm{R}^{2}=0.65\right)$} \\
\hline & 5 & 2.61 & 0.12 \\
\hline \multicolumn{4}{|l|}{ Effect tests } \\
\hline Temperature variation & 1 & 0.08 & 0.78 \\
\hline Longitude & 1 & 0.12 & 0.72 \\
\hline Latitude & 1 & 0.86 & 0.38 \\
\hline Latitude $\times$ Longitude & 1 & 0.45 & 0.53 \\
\hline Current speed & 1 & 6.39 & 0.04 \\
\hline \multicolumn{4}{|c|}{ (b) Whole model: selected variables $\left(R^{2}=0.61\right)$} \\
\hline & 3 & 4.6 & 0.03 \\
\hline \multicolumn{4}{|l|}{ Effect tests } \\
\hline Temperature variation & 1 & 1.4 & 0.27 \\
\hline Longitude & 1 & 1.5 & 0.26 \\
\hline Current speed & 1 & 9.8 & 0.01 \\
\hline
\end{tabular}


likely to reflect normal acclimatization; moderate events may promote adaptive responses of the coral ecospecies (Buddemeier et al. 2004), while rare extreme events may create large-scale mortality (McClanahan 2004) and dramatic shifts in host and/or symbiont communities (Baker et al. 2004). Nonetheless, acclimatization and adaptation indicate stressful conditions and the earlier these signs are detected, the more likely it is that an organism is approaching a homeostatic imbalance between the Symbiodinium and coral host. Consequently, it is likely that the BIs reported here predict those taxa that are most likely to decline with projected increases in temperature, with some possibly important exceptions such as the few coral taxa that do not bleach from warm water but nonetheless die and those that bleach but do not die (McClanahan 2004).

\section{Site-specific responses}

Variability in the bleaching response at different sites indicated that bleaching was positively associated with high water flow and that this response reflected differences in an organism's response, and was not simply a reflection of local coral community structure. The independence between organism and community is largely attributable to the moderately high uniformity in the coral communities at most of the study sites as reflected in the high percentage of variance (91\%), attributed to the first 2 principal component axes of the coral community composition data. Water flow and BI were moderately negatively correlated with temperature variation but these relationships were not strong. In both cases, local factors and the spatial resolution of the water temperature measurements may have overridden the ability to detect strong patterns in these 2 variables. For example, some sites, particularly on the eastern side of the island, were variable in their distance from shore and protection from major currents. These differences were detected by the water flow method but not by the NOAA satellite data.

The spatial resolution of the satellite data was too coarse to differentiate all of the sites, particularly along short onshore to offshore distances. For example, the GRSE location had 3 sites that had BIs of 18.8, 24.9 and 36.5 along an onshore to offshore gradient; these sites spanned $0.04^{\prime}$ of longitude and the measured water flow followed this BI gradient from 13.7, 14.8 and $19.4 \mathrm{~cm} \mathrm{~s}^{-1}$. Nonetheless, because of their close proximity, they were characterized by the same satellite temperature data. We suspect that the actual temperature variation between these sites was different and that if the temperature data were more closely associated with the study sites than the relationship between the $\mathrm{BI}$, water flow and temperature variation would be stronger. This problem prevents us from clearly determining which environmental factor, water flow or temperature variation, is responsible for the observed bleaching patterns, as they co-vary with unmeasured environmental factors. Nonetheless, it is reasonable to assume that environmental stress to corals is reduced with higher water flow (Nakamura \& van Woesik 2001), particularly in these shallow wave- and currentprotected back-reef locations where water flow is likely to be obstructed and possibly a limiting factor of coral growth. The multiple regression analysis also distinguished water flow as the dominant environmental influence on the BI.

Water flow has anecdotally been suggested by a number of investigators to improve environmental conditions and provide resistance to coral bleaching (summarized by West \& Salm 2003). Experimental work has shown that corals held in flume tanks with higher water flow have lower bleaching responses (Nakamura \& van Woesik 2001) and faster recovery from bleaching (Nakamura et al. 2003). Consequently, our field results would appear to contradict these findings, except that responses can vary considerably depending on the environmental history and associated acclimatization of experimental organisms. For example, Nakamura \& van Woesik (2001) removed Acropora digitifera from a high water flow environment in the field, and after $2 \mathrm{wk}$ in a low-flow tank they exposed coral pieces to high light to induce bleaching; survival was low in the low-flow environment suggesting a greater stress response in this environment. In these types of experiments, it is often difficult to know how the response might vary as a function of the source environment of the experimental organism and whether or not a $2 \mathrm{wk}$ acclimation period is sufficient to re-acclimate an organism adapted to a different source environment. Unless organisms are taken from different source environments and exposed to the same and opposite environments in laboratory-based stress experiments in a reciprocal design, it is difficult to discount the role of the original source environment on experimental outcomes.

A study of coral community response to the rare 1998 ENSO in Kenya found that coral cover was reduced most in reefs with the most stable background temperatures but that species richness was maintained after a temporary loss (McClanahan \& Maina 2003). Reefs with high background variation in temperatures had stable coral cover and community composition of dominants across the rare disturbance, but lost rare members of the community. This field-based finding is more concordant with the findings presented here in that the dominant organisms in the stable and less environmentally stressed environments were more susceptible 
to the anomalous high temperature. These findings and discussion highlight the unresolved differences between the benefits of a benign or stable environment versus acclimatization to a stressful environment on the responses of reef corals to environmental anomalies and projected climate change. Resolving this issue is important for prioritizing site-based conservation activities (West \& Salm 2003). Based on field studies in this region, we suggest that benign or stable environments will produce communities that are less resilient to rare climatic disturbances but if disturbances are sufficiently infrequent, they will maintain high numbers of species. Variable or stressed environments will maintain dominant organisms capable of withstanding climatic disturbances but will lose those rare members of the community that cannot adapt to the stressful conditions.

A finding reported here contradictory to the Kenyan study was that site-specific taxonomic richness in Mauritius increased towards the west where current speeds were lower and temperature variation higher. Consequently, site-specific taxonomic richness in Mauritius did not increase with physico-chemical stability, contradictory to the Kenyan findings. This may seem ironic, as Kenya is closer to the equator and reported standard deviations of temperature in lagoons range from 0.39 to 1.53 (McClanahan \& Maina 2003). These figures are considerably lower than those reported here for Mauritius, ranging from 1.73 to 1.82 . The likely reason is that the numbers of taxa in Mauritius also declined with increasing coral cover from $\sim 20$ to $60 \%$, whereas in Kenyan coral cover never exceeded $\sim 25 \%$ of the substratum. In Mauritian lagoons, the dominance of hard coral cover, notably created by large stands of Acropora and other taxa, appears to be most common on the eastern side of the island. It is likely that high coral cover has led to losses in taxonomic diversity through competitive exclusion (Connell 1979). This has been shown for Acropora dominance where overtopping other coral growth forms results in competitive losses of under-storey taxa (Baird \& Hughes 2000). In Mauritius, it is not Acropora alone that produces this effect but a combination of the dominant taxa that produce high coral cover. In the studied Kenyan sites described above, coral cover was low at $<25 \%$ of the substratum and, therefore, likely to reduce the chances for competitive interaction and exclusion. Consequently, competitive interactions between coral taxa can also influence patterns of diversity. Taken together, these studies indicate a hump-shaped diversity-abundance relationship and that rare disturbance can produce losses or gains in diversity depending on the cumulative effect of the disturbance on the competitive dominants and subordinates, and their interactions.

\section{CONCLUSIONS}

Coral reefs in Mauritius appear to have been spared much of the disturbance that has affected the larger tropical western Indian Ocean (Goreau et al. 2000). Coral cover is high $(\sim 60 \%)$ and appears to have increased from the $44 \%$ cover reported from another broad survey in these and other Mauritian lagoons in 1992 (Ministry of Fisheries and Marine Resources 1998). The current dominant coral genera Acropora and Montipora are taxa known to bleach and die in warm water (McClanahan 2004), and the Symbiodinium clades also reflect an unstressed thermal environment (Baker 2004). These findings do not support predictions for this region based on historical temperature and future temperature projections (Sheppard 2003). Sheppard's (2003) model predicts a faster demise for reefs south of the equator than for those north of the equator. This contrasts with data on coral cover in the western Indian Ocean, where the highest declines in coral cover have occurred in the Maldives and Seychelles (Goreau et al. 2000, McClanahan 2000), while Mauritius and South Africa have reported increases in coral cover (this study and M. Schleyer's data reported in Goreau et al. 2000). This suggests a need to re-evaluate the basis for these predictions and the relationship between temperature variability, coral acclimatization and mortality. Because Sheppard's (2003) model was based on temperatures in 1998 and these were not destructive to Mauritian reefs, it will not be able to accurately predict future mortality patterns in this area. Currently, these reefs appear to have been spared destructive climatic disturbances and may be a refuge for temperature-sensitive taxa. Consequently, increased efforts to conserve them and their resilience are of regional importance.

Acknowledgements. This work was supported by the Wildlife Conservation Society and formed part of a collaborative project with the Mauritius Oceanography Institute. We are grateful for assistance in the field by C. Samyan and Coast Guard personnel, and in the laboratory by $H$. Wirshing, N. Muellehner and S. Jones, and to G. Liu for assistance with the NOAA satellite data.

\section{LITERATURE CITED}

Anzai R (2001) The effects of coral morphology and waterflow rates on rates of coral growth and passive diffusion. MSc thesis, University of the Ryukyus

Baird AH, Hughes TP (2000) Competitive dominance by tabular corals: an experimental analysis of recruitment and survival of understorey assemblages. J Exp Mar Biol Ecol 251:117-132

Baird AH, Marshall PA (2002) Mortality, growth and reproduction in scleractinian corals following bleaching on the Great Barrier Reef. Mar Ecol Prog Ser 237:133-141

Baker AC (1999) The symbiosis ecology of reef-building 
corals. PhD thesis, University of Miami, Coral Gables, FL Baker AC (2001) Reef corals bleach to survive change. Nature 411:765-766

Baker AC (2004) Symbiont diversity on coral reefs and its relationship to bleaching resistance and resilience. In: Rosenberg E, Loya Y (eds) Coral health and disease. Springer Verlag, Berlin, p 177-194

Baker AC, Rowan R (1997) Diversity of symbiotic dinoflagellates (zooxanthellae) in scleractinian corals of the Caribbean and eastern Pacific. Proc 8th Int Coral Reef Symp, Panama 2:1301-1305

Baker AC, Rowan R, Knowlton N (1997) Symbiosis ecology of two Caribbean acroporid corals. Proc 8th Int Coral Reef Symp, Panama 2:1295-1300

Baker AC, Starger CJ, McClanahan TR, Glynn PW (2004) Corals' adaptive response to climate change. Nature 430: 741

Berkelmans R, De'ath G, Kininmonth S, Skirving W (2004) A comparison of the 1998 and 2002 coral bleaching events on the Great Barrier Reef: spatial correlation, and predictions. Coral Reefs 23:74-83

Buddemeier RW, Baker AC, Fautin DG, Jacobs JR (2004) The adaptive bleaching hypothesis. In: Rosenberg E, Loya Y (eds) Coral health and disease. Springer Verlag, Berlin, p 427-444

Connell JH (1979) Intermediate-disturbance hypothesis. Science 204:1344-1345

Doty MS (1971) Measurement of water movement in reference to benthic algal growth. Bot Mar 14:32-35

Edmunds PJ, Gates RD, Gleason DF (2003) The tissue composition of Montastraea franksi during a natural bleaching event in the Florida Keys. Coral Reefs 22:54-62

Fagoonee I, Wilson HB, Hassell MP, Turner JR (1999) The dynamics of zooxanthellae populations: a long-term study in the field. Science 283:843-845

Fitt WK, Brown BE, Warner ME, Dunne RP (2001) Coral bleaching: interpretation of thermal tolerance limits and thermal thresholds in tropical corals. Coral Reefs 20:51-65

Gates RD, Edmunds PJ (1999) The physiological mechanisms of acclimatization in tropical reef corals. Am Zool 39:30-43

Gleason MG (1993) Effects of disturbance on coral communities: bleaching in Moorea, French Polynesia. Coral Reefs 12:193-201

Glynn PW, de Weerdt WH (1991) Elimination of two reefbuilding hydrocorals following the 1982-83 El Niño warming event. Science 253:69-71

Goreau T, McClanahan T, Hayes R, Strong A (2000) Conservation of coral reefs after the 1998 global bleaching event. Conserv Biol 14:5-15

Hardman ER, Meunier S, Turner JR, Lynch TL, Taylor M, Klaus R (2004) The extent of coral bleaching in Rodrigues, 2002. J Nat Hist 38:3077-3089

Hoegh-Guldberg O, Salvat B (1995) Periodic mass-bleaching and elevated sea temperatures: bleaching of outer reef slope communities in Moorea, French Polynesia. Mar Ecol Prog Ser 121:181-190

Jokiel PL (2004) Temperature stress and coral bleaching. In: Rosenberg E, Loya Y (eds) Coral health and disease. Springer Verlag, Berlin, p 401-425

McClanahan TR (2000) Bleaching damage and recovery potential of Maldivian coral reefs. Mar Pollut Bull 40: 587-597

Editorial responsibility: Otto Kinne (Editor-in-Chief), Oldendorf/Luhe, Germany
McClanahan TR (2004) The relationship between bleaching and mortality of common corals. Mar Biol 144:1239-1245

McClanahan TR, Maina J (2003) Response of coral assemblages to the interaction between natural temperature variation and rare warm-water events. Ecosystems 6: 551-563

McClanahan TR, Muthiga NA (1992) Comparative sampling of epibenthic subtidal gastropods. J Exp Mar Biol Ecol 164: 87-101

McClanahan TR, Shafir SH (1990) Causes and consequences of sea urchin abundance and diversity in Kenyan coral reef lagoons. Oecologia 83:362-370

McClanahan TR, Muthiga NA, Mangi S (2001) Coral and algal changes after the 1998 coral bleaching: interaction with reef management and herbivores on Kenyan reefs. Coral Reefs 19:380-391

McClanahan TR, Baird AH, Marshall PA, Toscano MA (2004) Comparing bleaching and mortality responses of hard corals between southern Kenya and the Great Barrier Reef, Australia. Mar Pollut Bull 48:327-335

Ministry of Fisheries and Marine Resources (1998) Status of coral reefs and physico-chemical characteristics of nearshore waters of Mauritius: a baseline study. Albion Fisheries Research Institute, Albion, Mauritius

Montaggioni LF, Faure G (1997) Response of reef communities to sea-level rise: a Holocene model from Mauritius (Western Indian Ocean). Sedimentology 44:1053-1070

Moothien Pillay R, Terashima H, Kawasaki H (2002) The extent and intensity of the 1998 mass bleaching event on the reefs of Mauritius, Indian Ocean. Galaxea 4:43-52

Nakamura T, van Woesik R (2001) Differential survival of corals during the 1998 bleaching event is partially explained by water-flow rates and passive diffusion. Mar Ecol Prog Ser 212:301-304

Nakamura T, Yamasaki H, van Woesik R (2003) Water flow facilitates recovery from bleaching in the coral Stylophora pistillata. Mar Ecol Prog Ser 256:287-291

Ragoonaden S (1997) Impact of sea level rise on Mauritius in Island States at risk: global climate change, development and population. J Coastal Res 24:221-230

Sall J, Lehmaan A, Creighton L (2001) JMP Start Statistics. Thomson Learning, Duxbury

Seutin G, White BN, Boag PT (1991) Preservation of avian blood and tissue samples for DNA analyses. Can J Zool 69: $82-90$

Sheppard CRC (2003) Predicted recurrences of mass coral mortality in the Indian Ocean. Nature 425:294-297

Turner JR, Hardman E, Klaus R, Fagoonee I, Daby D, Baghooli R, Persands S (2000) The reefs of Mauritius. In: Sounter D, Obura DO, Linden O (eds) Coral reef degradation in the Indian Ocean: status report 2000. Stenby Offset, Vasteras, p 94-107

West JM, Salm RV (2003) Resistance and resilience to coral bleaching: implications for coral reef conservation and management. Conserv Biol 17:956-967

Wilkinson C, Linden O, Cesar H, Hodgson G, Rubens J, Strong AE (1999) Ecological and socioeconomic impacts of 1998 coral mortality in the Indian Ocean: an ENSO impact and a warning of future change? Ambio 28:188-199

Yap HT (2004) Differential survival of coral transplants on various substrates under elevated water temperatures. Mar Pollut Bull 49:306-312

Submitted: October 6, 2004; Accepted: March 31, 2005

Proofs received from author(s): July 22, 2005 